\title{
Primary multiple spinal extradural hydatid cysts of the literature: case report and review
}

\author{
M Bavbek MD, S Inci MD, K Tahta MD, V Bertan MD \\ Hacettepe University School of Medicine, Department of Neurosurgery, Bakaliklar, \\ Ankara, Turkey.
}

In this paper a patient with primary multiple extradural hydatid disease is described. He had no neurological deficits, although there were numerous hydatid cysts located at the thoracic 7-9 level extradurally. Nuclear magnetic resonance (NMR) was used for what would appear to be the first time for the diagnosis of spinal hydatid disease.

Key words: hydatid disease; spine; nuclear magnetic resonance.

\section{Introduction}

Hydatid disease occurs in humans from the contamination of water and foodstuffs. ${ }^{1,2}$ It rarely affects the bones: $0.5-2 \%$ of all cases of hydatidosis. ${ }^{3,4}$ The spine is involved in $44 \%$. The disease is seldom seen in developed countries, but may occur in various countries including Turkey, where it is the cause of spinal cord compression in $3.8 \%$. ${ }^{3.5}$ According to Arana-Iniguez and LopezFernandez the incidence of hydatid disease of the vertebral column is $8.5 \% .^{6}$ It mostly affects the lumbar, thoracic and cervical regions respectively ${ }^{7}$ and begins as a single primary cyst which contains daughter cysts. Rupture of a cyst into the muscles may be followed by secondary hydatid cysts. Sometimes these may be forced by muscle movements some distance along the vertebral column or in the connective tissue planes, similar to what occurred in our patient. ${ }^{8}$

\section{Case report}

A forty year old farmer was transferred from the Social Security Hospital to the outpatient department of our clinic with a 6-month history of back pain and a subcutaneous mass in the upper thoracic region. The mass was totally excised in that hospital and the pathology study showed it to be a

Correspondence: Karanfil Sokak, Beton Apt. 34/1, Bakanliklar, Ankara, Turkey. hydatid cyst. A CT scan was performed in that hospital, and demonstrated multiple spinal, paraspinal and paravertebral cysts. He was admitted to our hospital where

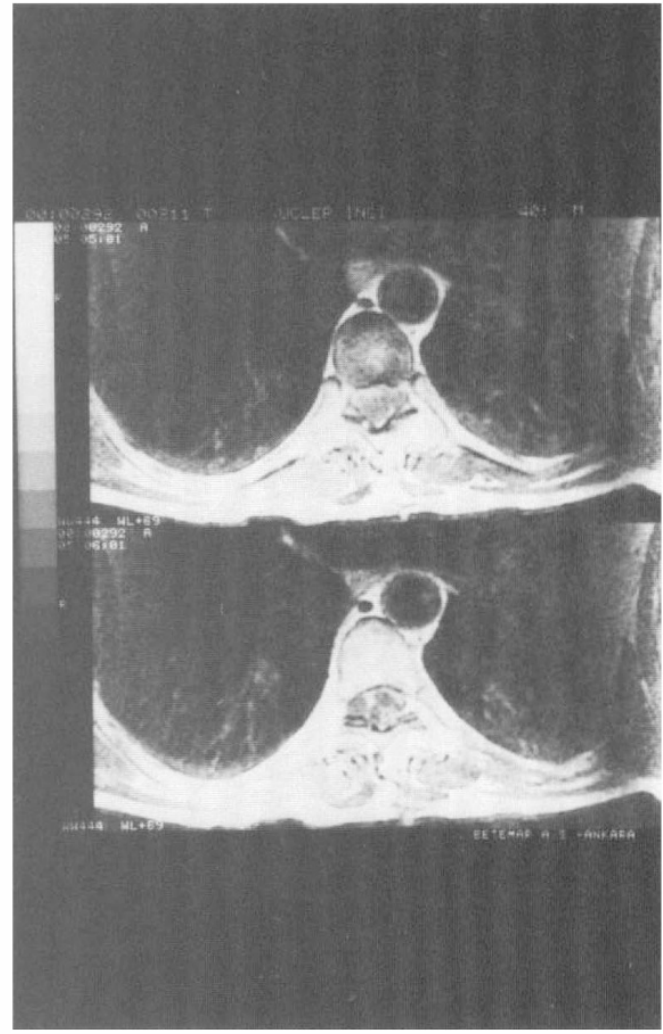

Figure 1 NMR examination: multiple paraspinal cysts seen on the axial plane at the level of $\mathrm{T} 8$. 
clinical examination showed a $3 \times 5 \mathrm{~cm}$ fluctuant subcutaneous mass at the T5-6 level, on palpation, laterally on the left side; and a $1 \times 2 \mathrm{~cm}$ subcutaneous mass was palpated $10 \mathrm{~cm}$ laterally on the right side. The neurological examination was totally normal, as was the routine laboratory examination. Plain $x$-rays of the spine showed minimal erosion of the $\mathrm{T} 7$ lamina. Plain $\mathrm{X}$-rays of the lung were normal, and abdominal ultrasonography was normal. The NMR examination revealed numerous cysts located extradurally all along the vertebrae at T7-9 level and subcutaneous cysts were located bilaterally at T3 level (Figs 1 and 2). An operation was carried out, and a $3 \times 5 \mathrm{~cm}$ infected subcutaneous cyst was excised at the T3 level on the left lateral aspect and another measuring $2 \times 1 \mathrm{~cm}$, an infected subcutaneous cyst, was excised on the right

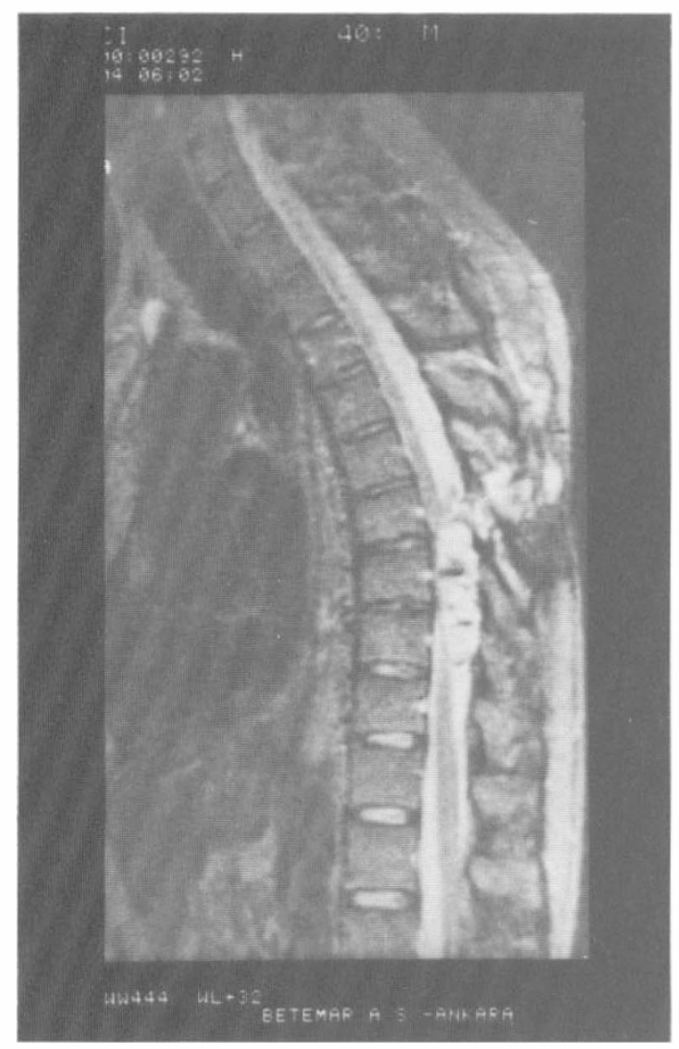

Figure 2 NMR examination: numerous extradural cysts shown along the T7-9 vertebrae, and subcutaneous cysts at T3 level, in the saggital plane. lateral side. Multiple cysts were located and removed paravertebrally. A T7-9 laminectomy was performed and multiple cysts were seen in an extra pouch located right extradural laterally and were grossly removed (Fig 3). The operation area was soaked with $3 \% \mathrm{NaCl}$ wetted patties for a few minutes, which were then removed and the area was washed with normal $0.09 \% \mathrm{NaCl}$. After the operation the neurological examination remained normal. The patient was given mebendazole orally for one year, without any side effects.

\section{Discussion}

The incidence of vertebral hydatid disease is less than hepatic and pulmonary involvement. Primary vertebral hydatid disease without any other systemic involvement can occur if there are direct porto-vertebral venous shunts. ${ }^{9}$ In the literature one-third

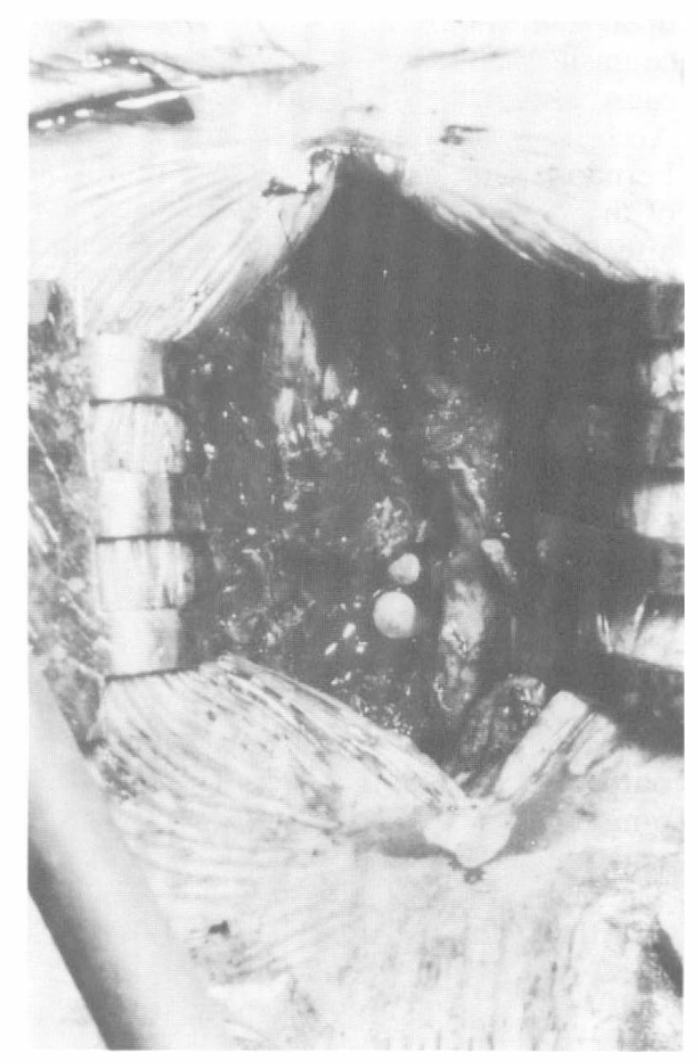

Figure 3 Multiple cysts seen during operation. 
of the patients had previously undergone surgery for their cysts. ${ }^{5}$ Our patient had a history of cyst resection, and coincidentally hydatid disease was diagnosed. Further investigations were then made to obtain the exact site(s) of the lesion(s). In the literature all of the patients had neurological disturbances ${ }^{3-5}, 8-10$ but in our patient the neurological examination was completely normal. If there are no neurological signs, the diagnosis is difficult. Nowadays a CT scan can visualise bone destruction, cord compression and paravertebral cysts, but how can the level of the CT scan be diagnosed if no neurological signs are present? However NMR can provide a full image of the vertebral axis of the spinal canal, and thus reveal the full spinal extent of the disease. We are unaware of any other NMR study of hydatid cyst disease previously reported. This is the first study to be reported, and it shows that in complicated clinical situations the exact level cannot be precisely defined, though NMR is most helpful. It also demonstrates the cyst contents, including daughter scolices and hydatid sand. ${ }^{2}$ Surgical extirpation is the only possible treatment for spinal hydatid disease as there is a great risk of spinal cord compression. The benzimidazole derivative mebendazole has a known lethal effect on secondary E Granulosis cysts; ${ }^{9}$ thus it can be used in the pre, peri and postoperative periods.

\section{References}

1 Stern W, Stern WE (1985) Parasitic infestations In: Wilkins RH, Rengechery SS, editors. Neurosurgery. Vol. 3. McGraw-Hill Book Company, New York: 2010-2015.

2 Sze G (1988) Infections and inflammatory diseases. In: Stark DD, Bradley WG, editors. Magnetic Resonance Imaging. The C V Mosby Company, St Louis, Washington DC: 322.

3 Bettaieb A, Khaldi M, Ben Rhoumo T, Touibi S (1978) L'Echino coccose Vertebro-Medullaire à propos de 32 cas. Neurochirgie 24, 205-210.

4 Kaoutzanis M, Anagnostopoulos D, Apostolou A (1989) Hydatid disease affecting the vertebrae. Acta Neurochir (Wien) 98: 60-65.

5 Pamir MN, Akalan N, Ozgen T, Erbengi A (1984) Spinal hydatid cysts. Surg Neurol 21: 53-57.

6 Arana-Iniguez R, Lopez Fernandez JR (1967) Parasitosis of the nervous system with special reference to echinococcosis. Clin Neurosurg 14: 123-144.

7 Apt WL, Fierro JL, Calderon C, Peraz C, Mujica P (1976) Vertebral hydatid disease. Clinical experience with 27 cases. J Neurosurg 44 (1): 72-76.

8 Mills JJ (1956) Paraplegia due to hydatid disease. J Bone Joint Surg 38: 884-891.

9 Fiennes AG, Thomas DG (1982) Combined medical and surgical treatment of spinal hydatid disease: a case report. J Neurol Neurosurg Psychiatry 45 (10): 927-931.

10 Wani MA, Taheri SA, Babu ML, Ahangar GA, Wani Haseeni (1989) Primary spinal extradural hydatid cyst. Neurosurgery 24 (2) 631-632. 